\title{
PREDICTING EUROPEAN RED MITE EGG HATCH ON APRICOTS 1. A DEGREE-DAY MODEL.
}

\author{
M.G. HILL and G.F. McLAREN
}

Entomology Division, DSIR, Auckland and Clyde, Central Otago

\section{SUMMARY}

In Central Otago, European red mite (Panonychus ulmi) damage young apricot fruits unless controlled soon after the winter eggs hatch. Field data collected between 1978 and 1983 showed a variation of 14 days in the date of $50 \%$ winter egg hatch. These data were used to develop a model to predict the hatching curve of ERM winter eggs. Predictions correlated well with field data collected in 1984 and 1985. The model was used along with predictions of temperatures from the Meteorological Service, to provide a spray forecasting service for Central Otago apricot growers in 1986 and 1987.

\section{INTRODUCTION}

European red mite (ERM), Panonychus ulmi Koch, causes cosmetic damage to apricot fruits (particularly cv. Moorpark), when immature stages feed on developing fruit in spring (McLaren 1980; 1983). Mites must be controlled soon after winter eggs have hatched if fruit blemishing is to be avoided and ideally, chemical sprays should be applied not earlier than 2 days and not later than 3 days from the date when $50 \%$ of the eggs have hatched (McLaren 1983). For several years, winter egg hatch has been monitored by regular visual inspection of winter eggs on apricot (McLaren 1985). This method is labour intensive and only records the event after it has occurred, rather than predicting it.

Accumulated degree-days have been used widely to predict seasonal development and emergence of various arthropods. This paper describes an iterative technique for analysing ERM winter egg hatch data to provide predictions of the timing of the cumulative egg hatching curve.

\section{METHODS}

The basic requirements for predicting phenological events using degree-day accumulation are $i$. field observations of the event; ii. determination of the base temperature and starting date for degree-day accumulation, iii. a formula for calculating degree-days accumulated each day and iv. a method for predicting temperatures.

Field observations of ERM winter egg hatch.

Data have been collected yearly (by GFM) since 1978 . They consist of observations on several groups of 10-50 winter eggs on the bark of unsprayed apricot trees made at 3-4 day intervals from late September to mid October. On each sampling occasion, numbers of hatched eggs were recorded. After hatching was completed, the number of inviable eggs was recorded. Details of the method and cumulative hatching curves constructed from the data are reported in detail elsewhere (McLaren 1980; 1985).

Determining the base temperature and starting date.

The empirical method of Ring and Harris (1983) has been used. This is an iterative process which finds the optimal combination of base temperature and starting date to minimise the summed deviations between observed and predicted events for data collected over several years. The events of interest were the days corresponding to the 10th, 25th, 50th, 75th and 90th percentile points on the ERM winter egg hatch curve. These dates were obtained for each year from 1978 to 1985 .

Considering first the estimation of the date of $50 \%$ egg hatch; the mean number of

Proc. 41st N.Z. Weed and Pest Control Conf. 
degree-days accumulated above all base temperature threshold from $-5^{\circ} \mathrm{C}$ to $+10^{\circ} \mathrm{C}$ and all starting dates from July 20 to September 8 were calculated, for the 6 years of data from 1978 to 1983 . These mean degree-day values were then used to predict the $50 \%$ hatch date (July $1=$ day 1 ) for each of the 6 years. The summed deviations of the observed minus predicted date for the 6 years data then gave an estimate of the accuracy of the prediction for each particular combination of starting date and base temperature.

An iterative procedure was used to select the combination of starting date and base temperature which gave the smallest root mean square error ((RMSE) an appropriate unbiased estimate of average deviation) of observed minus predicted date of $50 \%$ egg hatch summed over the 6 years. The same procedure was used to find the best combinations of base temperature and starting date to predict the 4 remaining percentile points of the ERM egg hatching curve. Thus, each of the percentile points has its own unique combination of starting date and base temperature.

The resulting figures for starting date, base temperature and degree-day accumulation for each of the 5 percentiles were used to predict the ERM egg hatching curves for 1984 and 1985.

\section{Calculating degree-day accumulation}

Two methods of daily degree-day accumulation were used. These used the simple mean temperature, calculated from (maximum + minimum) $/ 2$ and a sine curve fitted between daily maximum and minimum measurements (Allen 1976). The first, simpler, method gave smaller RMSE values.

Daily maximum and minimum temperature measurements were from the New Zealand Meteorological Service site at the DSIR Clyde Research Orchard from 1983 to 1986. Simultaneous observations after the change to Clyde showed that both sites have very similar temperature measurements.

\section{Predicting temperature}

Predictions of maximum and minimum temperatures for 5 days in advance were provided by the Meteorological Service, using output from a model of global weather systems. For predictions of temperatures greater than 5 days in advance, mean temperatures calculated from historical data were used (M.J. Salinger pers. comm.).

In 1986 and 1987, the model was used to provide a forecast for growers, giving a minimum of 1 week's notice of the predicted spraying date. The spraying date given to growers was the predicted $50 \%$ hatch date. Advice was disseminated via local media. This advice has been given in previous years, without the aid of temperature prediction, but based upon the actual observations of the start of ERM egg hatch. The hatch of ERM on apricot trees was again monitored in 1986 and 1987 to provide an indication of the accuracy of the forecast.

\section{RESULTS}

The optimal base temperature, starting date and average degree-days to all 5 observed percentile hatch points using data for the 6 years between 1978 and 1983 (Table 1) were used (together with actual historical temperatures) to predict the hatching curves in 1984 and 1985 . There was close agreement between observed and predicted hatching curves in these years (Fig. 1).

The 8 years of data from 1978 to 1985 were used to recalculate the figures, to provide predictions using all of the available historical data (Table 1). The model retrospectively gave accurate predictions of the observed $50 \%$ hatch date in every year from 1978 to 1985 (Table 2).

In 1986, a 'real time' prediction was given 1 week in advance of the event using predicted maximum and minimum temperatures supplied by the Meteorological Service. A close agreement between observed and predicted cumulative hatch was obtained (Fig. 1). For the purposes of grower spraying date prediction, the $50 \%$ hatch point was given as the recommended spraying date. The predicted date agreed with the actual date (October 15) in 1986. In 1987 only the $50 \%$ hatch date and not the whole hatching curve was predicted in advance. This was 1 day earlier than the actual $50 \%$ hatch date (October 11). Thus, in both years in which the model has been used to provide spraying recommendations to growers, the predictions have been within the 
level of accuracy required (i.e., not later than 3 days and not earlier than 2 days of the true $50 \%$ hatch date).

TABLE 1: Optimal base temperatures, starting dates, degree-days to the events and root mean squrae error (RMSE) for 5 percentiles of the ERM winter egg cumulative hatching curve. A: using 6 years historical data and B: using 8 years historical data.

\begin{tabular}{ccccc}
\hline $\begin{array}{c}\text { \%0 ERM } \\
\text { Egg Hatch }\end{array}$ & $\begin{array}{c}\text { Base } \\
\text { Temperature } \\
{ }^{\circ} \mathrm{C}\end{array}$ & $\begin{array}{c}\text { Start } \\
\text { Day }\end{array}$ & $\begin{array}{c}\text { Degree-Days } \\
\text { To Event }\end{array}$ & RMSE \\
\hline A: $1978-1983:$ & & & & \\
$10 \%$ & 1 & 25 August & 329 & 1.18 \\
$25 \%$ & 1 & 25 August & 356 & 1.12 \\
$50 \%$ & 3 & 25 August & 282 & 1.40 \\
$75 \%$ & 4 & 23 August & 255 & 1.70 \\
$90 \%$ & 3 & 10 August & 358 & 0.69 \\
& & & & 1.02 \\
B: $1978-1985:$ & 1 & 25 August & 329 & 1.01 \\
$10 \%$ & 1 & 25 August & 356 & 1.29 \\
$25 \%$ & 3 & 25 August & 283 & 1.00 \\
$50 \%$ & 3 & 23 August & 307 & \\
$75 \%$ & 3 & 22 August & 330 & \\
$90 \%$ & 3 & & & \\
\hline
\end{tabular}

TABLE 2: Deviations (in days) between observed and predicted 50\% ERM winter egg hatching dates over 8 years. (Negative deviations are later than observed).

\begin{tabular}{cccccccccc}
\hline & \multicolumn{8}{c}{ Year } \\
& 1978 & 1979 & 1980 & 1981 & 1982 & 1983 & 1984 & 1985 \\
\hline Deviation & 0 & 2 & -1 & 1 & 1 & -2 & 0 & 0 \\
\hline
\end{tabular}

\section{DISCUSSION}

If several years phenology data are available, this iterative method offers an excellent alternative to more traditional ways of predicting phenological events (i.e., development rate models based upon laboratory observation of development at different temperatures). It makes no assumptions about threshold temperatures or starting times for degree-day accumulations, and does not require the collection of laboratory development rate data. One disadvantage of this approach may be that, because it is completely empirical, it is unlikely to be transportable between regions. For example, daily variations in temperature are greater in Central Otago than in maritime fruitgrowing areas in the North Island (e.g. Hawke's Bay), and daily temperature profiles in spring are also different. However, Ring et al (1983) have shown that by using suitable correction factors, the area over which predictions are valid may be extended. The model's greatest limitation is that it requires a minimum of 4-6 years field data as a basis for making predictions.

This method of forecasting ERM hatch will replace the more labour intensive method of visual observation used previously. It has an additional advantage in that visual observation does not allow the true hatching curve to be determined accurately until after hatching is complete because of variations in the proportion of inviable eggs which occur from year to year. In most years, percentage hatch varied from 50\% $-91 \%$ but in 1986 and 1987 , only $10 \%$ and $12 \%$ respectively of eggs were viable. Forecasting of the $50 \%$ hatch date in these years would have been very difficult without the use of this model. 


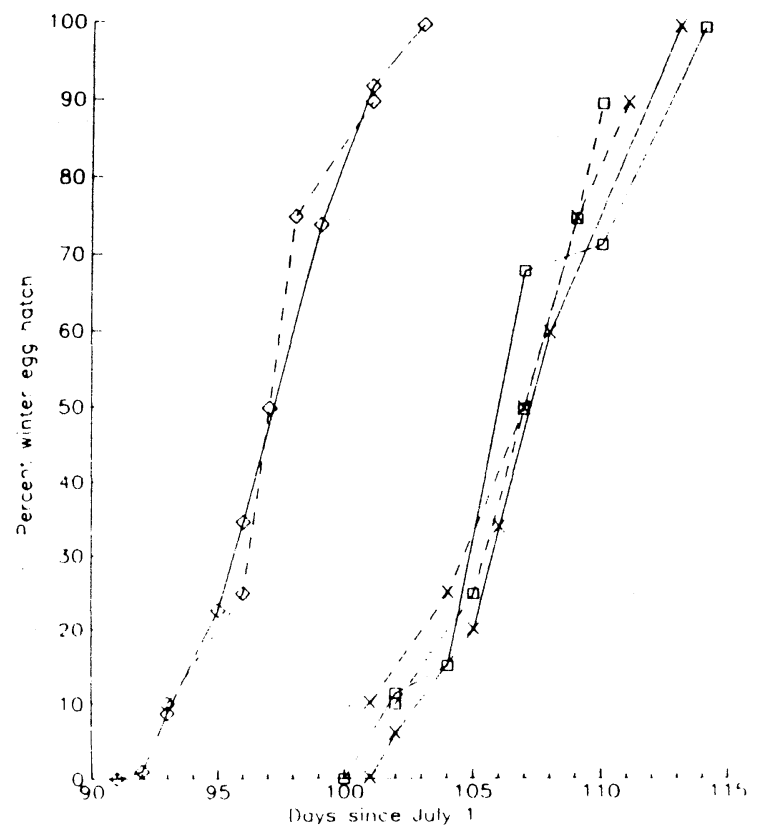

Fig. 1: Observed (solid lines) and predicted (dashed lines) hatching curves for ERM winter eggs for $1984(\square), 1985(\diamond)$ and $1986(X)$. In the first two years predictions were retrospective and made using actual weather data. In 1986, the predicted curve was produced 8 days in advance of actual hatch, using temperature predictions from the Meteorological Service.

\section{ACKNOWLEDGEMENTS}

Dr. M.J. Salinger and Mr. J. Renwick of the New Zealand Meteorological Service provided the temperature predictions for the forecasting service.

\section{REFERENCES}

Allen, J.C., 1976. A modified sine wave method for calculating degree days. Environmental Entomology, 45: 877-879.

McLaren, G.F., 1980. Timing of miticides for European red mite control on apricots in Central Otago. The Orchardist of New Zealand, October 1980: 305-306.

McLaren, G.F., 1983. Marking of apricots by European red mite (Panonychus ulmi [Koch]) - a control programme. New Zealand Journal of Experimental Agriculture, 11: 53-57.

McLaren, G.F., 1985. Control of European red mite Panonychus ulmi (Koch) on apricots in Central Otago, New Zealand. Proceeding of the 8th. International Symposium on Apricot Culture and Decline, Kecskemet, Hungary. Acta Horticulturae, 92: 251-260.

Ring, D.R. and Harris, M.K., 1983: Predicting pecan nut casebearer (Lepidoptera:Pyralidae) activity at College Station, Texas. Environmental Entomology, 12: 482-486.

Ring, D.R., Caldicote, V.R. et al - (10 other authors), 1983. Generalization and application of a degree-day model predicting pecan nut casebearer (Lepidoptera:Pyralidae) activity. Journal of Economic Entomology, 76: 831-835. 